Journal of Engineering and Applied Sciences 14 (10): 3472-3481, 2019

ISSN: 1816-949X

(C) Medwell Journals, 2019

\title{
A Research on the Energy Efficiency Operational Indicator EEOI using Taguchi Optimization Method for Bulk Carriers: A Case of Study in Vietnam
}

\author{
Tien Anh Tran \\ Faculty of Marine Engineering, Vietnam Maritime University, 180000 Haiphong, Vietnam
}

\begin{abstract}
The energy efficiency of ships plays a significant role in the field of fuel consumption reduction and sea environmental protection now a days. The International Maritime Organization (IMO) has a mission to ensure all ships both new ships and existing ships realiable operation in shipping transportation system. Hence, the Energy Efficiency Design Index (EEDI), Energy Efficiency Operational Indicator (EEOI) and Ship Energy Efficiency Management Plan (SEEMP) are energy efficiency measures that control technical measure and operational measure. In this research, the operational measure tool is referred as a main key to solve the energy efficiency of ships in operational activities. Energy Efficiency Operational Indicator (EEOI) is a main objective to conduct this research. The reduction of fuel consumption of engine and limitation of exhaust gas emissions from ship operational activities are equivalent to reduce the Energy Efficiency Operational Indicator (EEOI) value. Bulk carrier is chosen to express and collected the experimental data in aims with verifying the results collected. The optimization of experimental data of bulk carrier with certain name M/V NSU JUSTICE 250,000 DWT of VINIC shipping transportation company in Vietnam which is conducted in this research in order to increase the energy efficiency of ships. Taguchi optimization method is used to carry out this optimization throughout empirical operation of M/V NSU JUSTICE 250,000 DWT. The most suitable orthogonal array $\mathrm{L}_{9}$ was selected to determine the optimal experimental data of M/V NSU JUSTICE 250,000 DWT and to analyze the effects of these parameters. The proposed method has been discussed with Grey Relational Analysis (GRA) method for optimization of ships energy efficiency management. The study results will solve issue concerning about energy efficiency of ships as well as make an initial basis for next reseaches in the future.
\end{abstract}

Key words: Energy efficiency operational indicator, Taguchi optimization method, bulk carrier, fuel consumption, environmental protection, gas emissions

\section{INTRODUCTION}

It is suggested that reducing global Green-House Gas (GHG) emissions by $50-80 \%$ below 1990 levels by 2050 is necessary to stabilise the climate and avoid dangerous climate change impacts (IPCC, 2007). To avoid dangerous climate change, all the sectors of the global economy will be required to lower their GHG emissions. The global transport sector emissions represent around 13\% of global $\mathrm{CO}_{2}$ emissions of which total shipping $\mathrm{CO}_{2}$ emissions (from international and domestic shipping) accounted for just under 3\% (1 Gt) of global $\mathrm{CO}_{2}$ emissions in 2012 (Smith et al., 2014). "Low carbon shipping" describes a transition from the shipping industry's current levels of emissions and emissions intensity to low levels.

Now a days, there are various methods applied to improve the quality in variety of industries. In where Taguchi optimization method is one of the best optimization techniques to gain high quality without increasing cost. Taguchi optimization method is an optimal method that was introduced by Dr. Genichi Taguchi in Japan (Phadke, 1989). This is a simple, systematic and powerful method in aims with optimizing process parameters. The main objective of the Taguchi method is decreasing the effects of noise factors as well as determining the optimum level of the main controllable factors by considering the Taguchi's robust design (Zahraee et al., 2014). Besides that there are some previous researches concerning about transportation industries based on the Taguchi method. Unal et al. (1993) had applied Taguchi method in the field of space transportation vehicle to optimize a propulsion system design (Unal et al., 1993). Hence, the effects of some important design parameters for coal-water slurry in agitated vessel applied the Taguchi method along with Taguchi's $\mathrm{L}_{9}$ orthogonal array with each trial performed under the different levels of design parameter (Raguraman et al., 2013). In addition, the application of CFD (Computational Fluid Dynamic), Taguchi method and

Corresponding Author: Tien Anh Tran, Marine Research Institute, Vietnam Maritime University, 180000 Haiphong, Vietnam 
ANOVA (Analysis of Variance) technique are associated each other in aims with optimizing the combustion and emissions in a light duty diesel engine in field of marine engine (Xiao et al., 2014). Furthermore, Taguchi robust design with dynamic Signal to Noise ratio (S/N) and two step optimization process have been applied to optimize the head valve system for developing more efficient and low noise compressor (Park, 1996). Chlela et al. (2007) had used a statistical method in order to improve the energy efficiency of an office building (Chlela et al., 2007). An optimizational technique was adopted and based on the Design of Experiments (DOE) method. This method was used in the industrial field for process quality improvement and to improve its energy performance.

On the other hand, the Taguchi optimization method has been applied to some fields concerning about the engineering and machining. Pundir et al. (2018) had used Taguchi method for process parameters affecting biosorption that were optimized by adopting Analysis of Mean (ANOM) approach for maximizing the percentage removal of copper and nickel by growing Aspergillus sp. in batch reactor (Pundir et al., 2018). The procedure simulation of a lathe facing operation has been conducted by Taguchi method (Athreya and Venkatesh, 2012). Zheng et al. (2016) had also used Taguchi method to reduce the number of experiments required for validating the proposed model then his research and colleagues have conducted a mathematical model for surface roughness of ship hull grit blasting (Zheng et al., 2016). Besides that, Taguchi and Analysis of Variance (ANOVA) methods were applied to identify significant cutting parameters affecting the drill bit vibrations and surface roughness (Balaji et al., 2016).

In fact, the study of Taguchi method is still some limits in applying this method into shipping transportation industries because there are a few researches concern about shipping. So, in this research, the researcher has conducted to use Taguchi optimization method in aims with optimization of energy efficiency of ships. The actual data has been collected from a certain vessel of VINIC shipping transportation company in Vietnam with name M/V NSU JUSTICE 250,000 DWT. This is a big bulk carrier of company which operates regularly between Japan-Australia-Brazil. The results collected will be verified with experimental data of $\mathrm{M} / \mathrm{V}$ NSU JUSTICE 250,000 DWT.

\section{Literature review}

Some related works about energy efficiency of ships: Energy Efficiency Operational Indicator, EEOI is operational measure that is established by International
Maritime Organization IMO following the International Convention for the Prevention of Pollution from Ships (MARPOL 73/78) in particular Annex VI for prevention of air pollution from ships. The calculation of EEOI value is a fundamental work to determine this value at each ship in research process. Equation 1 will be showed in the field of computing EEOI value and it has made a background for some previous works (Buhaug et al., 2009).

$$
\mathrm{EEOI}=\frac{\sum_{\mathrm{j}} \mathrm{FC}_{\mathrm{j}} \cdot \mathrm{C}_{\mathrm{Fj}}}{\mathrm{m}_{\mathrm{c} \text { arg } .} \cdot \mathrm{D}}
$$

Where:

$\mathrm{FC}_{\mathrm{j}}=$ Stands for Consumed Fuel on voyage $\mathrm{j}$

$\mathrm{C}_{\mathrm{j}} \quad=$ Stands for the Carbon content of the fuel used

$\mathrm{m}_{\text {cargo }}=$ Stands for the mass of cargo transported

$\mathrm{D}=$ Stands for the Distance of voyage

EEOI principle is completely based on the ratio of mass of Carbon dioxide $\left(\mathrm{CO}_{2}\right)$ emission per unit of transport work. Vessel's specific operational data is important to compute EEOI value. The unit of EEOI will be determined by cargo carried (tonnes) and work done in case of container ships or passenger ships.

Some previous researches have been considered to use energy efficiency of ships to manage fuel oil consumption of engines and exhaust gases emission from ships. Coraddu et al. (2014) have been proposed the numerical investigation on ship energy efficiency management by Monte Carlo simulation method Coraddu et al. (2014). The evaluation of energy efficiency operational indicator EEOI through Monte Carlo simulation has been conducted. In additon, the total fuel oil consumption as a function of displacement and speed have been estimated like as random variables. A series of operation data have been collected during 2 years of RoPax vessel. Figari, $M$ and Soares, C.G have paid attention to the proper control strategy in aims with saving fuel consumption of engine and reducing exhaust gas emissions (Figari and Soares, 2009). A diesel engine or a gas turbine will drive marine propeller, normally using a controllable pitch propeller. This effective transmision will decide to the propulsion system in terms of power, consumption and emissions. In order to improve energy efficiency of ship this research had indicated that to move from the classical paradigm of 'static combinator curve of marine diesel engine and propeller to a 'dynamic set point of a propulsion plant. In addition, a "ship performance code" has been used to evaluate the potential benefit of the a "dynamic set point" control scheme.

On the other hand, the propulsion system dynamics is a key aspect which also preferred in research of Altosole et al (2012). The simulation methodologies have 


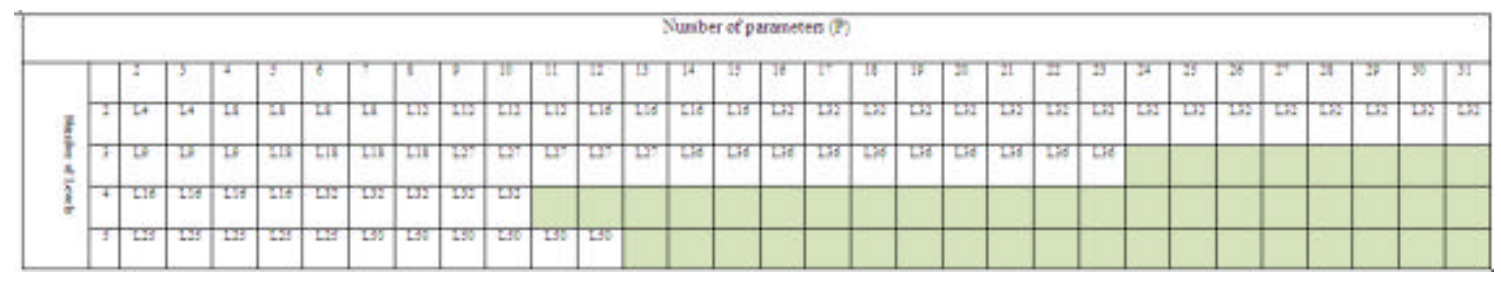

Fig. 1: Orthognal array

been used to present the marine propulsion plants and their control systems in aims with improving energy efficiency of ships through propulsion plants dynamic (Altosole et al., 2012). Besides that, Energy Efficiency Design Index (EEDI) is also applied effectively in the field of energy efficiency management for new ships. EEDI the Energy Efficiency Design Index is an energy efficiency measure tool that applies in the field of shipping transportation with the aim of measuring and evaluating of $\mathrm{CO}_{2}$ gas emission reduction from operation activities on ships such as equipment, engines and humans. Also, it is an index to assess the effectively equipment using through its value calculation (Tran, 2016). The EEDI creates a common metric to measure and improve new ship efficiency. This metric is calculated as the rate of Carbon dioxide $\left(\mathrm{CO}_{2}\right)$ emissions from a ship per transport work performed by the ship. $\mathrm{CO}_{2}$ emissions are directly related to energy efficiency and are calculated as fuel consumption multiplied by a fuel carbon factor. Transport work is calculated as a function of the cargo capacity of the ship and the design ship speed. Tran (2016) has conducted to calculate and assess a certain vessel about energy efficiency of ships that based on EEDI measure tool (Tran, 2016).

Also, having another research indicates to use energy flows onboard ships that considered in the time domain for complete ship energy systems simulation (Vassalos et al., 2014). This system allows interactions with component levels and accounting for different configurations, operating profiles, itineraries and environmental conditions. It also identified to demonstrate the methodology that leads to the evaluation of performance based on energy efficiency of ships. Banks et al. (2013) had explained the ship operation profiles in aims with improving energy efficiency operation activities (Banks et al., 2013). The operation profiles consist of voyage type distribution, speed distribution and draft distribution. Some results have been withdrawn from researching energy efficiency of ships. For instance, the time in port, sailing laden and sailing in ballast (no cargo voyage) will vary at each voyage. The wider range of operational speeds have been captured and had a trend towards low speed (slow steaming).
Johnson and Styhre had proposed the possibilities of reducing speed at sea through decreasing unproductive waiting time at berth (Johnson and Styhre, 2015). This is one of method in the field of improve energy efficiency of ship by reducing engine speed.

So as to overcome the previous related works for improving energy efficiency of ships, the novelty method for optimization of energy efficiency has been proposed in this research. Taguchi optimization method is an effective method in the field of optimizing the experiment data in production. This research will be a new trend to optimize the energy efficiency of ships in particular Energy Efficiency Operational Indicator (EEOI) value.

Taguchi optimization method: There are various methods used for improving the quality in variety of industries. Taguchi method is one of the best optimization techniques to achieve high quality without increasing cost (Zahraee et al., 2014). It is a simple, systematic and powerful method to increase the quality (Zahraee et al., 2014). The main objective of the Taguchi method is to decrease the effects of noise factors as well as determine the optimum level of the main controllable factors by considering the Taguchi's robust design (Zahraee et al., 2014). Orthogonal Array (OA) designs for allocating the chosen factors for experiment were applied by Taguchi. The most useful $O A$ designs are $\mathrm{L}_{8}, \mathrm{~L}_{16}$ and $\mathrm{L}_{18}$ (Antony, 1998). The orthogonal array has been chosen following Fig. 1. The materials include number of parameters and number of level that will be initial basis to determine the orthogonal array.

The orthogonal array is applied for calculating the main and interaction effects by running the minimum number of experiments (Taguchi, 1986). Taguchi method applies the Signal-to-Noise Rate (SNR) to minimize the effect of noise and optimize the process performance. In other words, the SNR is the response (output) of the experiment. In order to conduct the Taguchi method, different steps discussed subsequently should be followed (Antony and Antony, 2001).

Taguchi's techniques have been used widely in engineering design (Ross, 1996; Phadke, 1989). The Taguchi method contains system design, parameter 
design and tolerance design procedures to achieve a robust process and result for the best product quality (Taguchi, 1987 and 1993). The main trust of Taguchi's techniques is the use of parameter design (Ealey, 1994) which is an engineering method for product or process design that focuses on determining the parameter (factor) settings producing the best levels of a quality characteristic (performance measure) with minimum variation.

Design of Experiment (DOE) method has been developed in the early years of 20th century and has been extensively studied by statisticians, since, then but they were not easy to use by practitioners (Phadke, 1989). The approach of Taguchi optimization method is easy to be adopted and applied for users with limited knowledge of statistics. Hence, it has achieved a wide popularity in the engineering and scientific community. Taguchi method usually specifies three situations:

- Larger the better

- Smaller the better

- On-target, minimum-variation

Taguchi optimization method uses Signal-to-Noise $(\mathrm{S} / \mathrm{N})$ ratio as the quality characteristic of choice. $\mathrm{S} / \mathrm{N}$ ratio is used as measurable value instead of standard deviation. In this study, the optimization of energy efficiency of ship will be conducted by applying innovative method, Taguchi optimization method. With the advantages of Taguchi optimization method will be increased the high quality of optimization for operational paramters. In this case, the operational parameters will be analyzed and optimized for a certain object, a bulk carrier of VINIC shipping company in Vietnam. Furthermore, this Taguchi optimization method will reduce the noise factors of operational parameters of bulk carriers when navigation environment conditions impact such as wind speed, wave height, tidal current, temperature and pressure of outdoor environment.

The controllable factors need to determine in this research when applying Taguchi optimization method. The controllable factors will be a main parameter contributing the improvement of energy efficiency of ships. In this research, the enhancement of Energy Efficiency Operational Indicator (EEOI) value is a mission. In addition, the determination of main factors will help ship operators in the field of managing effectively their works.

The controllable factors include parameters following: the Heavy Fuel Oil (HFO) consumption of engine, Diesel fuel Oil (DO) consumption of auxiliary machineries, mass of cargo carried on board at each certain voyage and distance traveled, respectively.
One another side, the orthogonal array of Taguchi optimization method has been determined when the controllable factors and number of level have to describe clearly. The number of level of Taguchi optimization method are three corresponding to high, medium, low level when applying into this research. Since, three levels of Taguchi optimization method will be responded to three controllable positions of maine engine. Three controllable positions of marine diesel engine will be slow, half and full. These states control the mass of fuel oil that have been supplied into diesel engine. Furthermore, the appropriate energy consumption on ships will be a main part in the field of improving energy efficiency of ships. Taguchi optimization method is a reliable method in optimizing the operational process and experimental data. The orthogonal array of this reasearch will be identified based on Fig. 1 when the controllable factors and the number of level have deen determined. The certain values at each different level have been represented based on actual operation data of bulk carrier, M/V NSU JUSTICE 250,000 DWT in vietnam.

Besides that, Taguchi optimization method represents $\mathrm{S} / \mathrm{N}$ ratio. So, as to determine this $\mathrm{S} / \mathrm{N}$ ratio, the researcher has used Minitab analysis software to support in calculating this ratio. $\mathrm{S} / \mathrm{N}$ ratio has three types of optimization process. So, to optimize the energy efficiency of ship in this research, the concept "smaller the better" has been proposed. The improvement of energy efficiency of ship it needs to reduce fuel oil consumption of engine. This task will correspond to reduce the harmful gas emissions into environment.

Comparision between Taguchi optimization with traditional data mining methods: The overview of data mining methods and comparison with Taguchi optimization method will be introduced in this part. This comparison will indicate the superiority points of Taguchi optimization method in designing and optimizing the opertational data when noise factors impact. Data mining methods are the process of automatic exploring in large data (Tan et al., 2005). Data mining method does not have a theoretical expertise but this method needs to collect large amount of data in process. In contrast, Taguchi optimization method will deal this issue with having a suitable number of data can optimize those parameters.

Data mining consists of two categories following the objectives of algorithm, classification analysis and association analysis (Fig. 2 and 3).

Data mining method is divided into two different methods, classification and association analysis. Classification method which divides initial data into different classes is based on either the knowledge of 


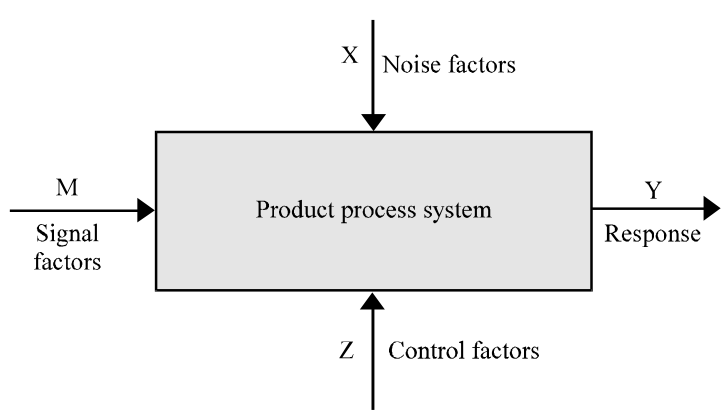

Fig. 2: Parameters diagram of a system

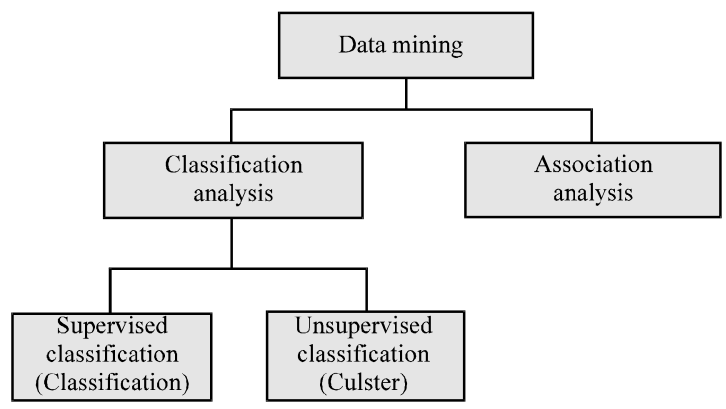

Fig. 3: The structure of data mining

predefined classes or structure of data set. Following the different situation that they are called as supervised classification and unsupervised classification (cluster), respectively. The association analysis method is usually applied for discovering interesting relationships which are called as association rules, hidden in large dataset.

Data mining method needs to build the mathermatical algorithm to classify the dataset along with understanding the characteristic of model. But Taguchi optimization method just needs calculate the Signal to Noise (S/N) ratio between the design of experiment with desired value. The desired value is completely taken from actual experiment data of certain study object.

In reality, Taguchi optimization method is an effective method in the field of optimizing the experiment data. This method is simple to apply than other data mining method. So, the researcher has been conducted this research with applying Taguchi optimization method in order to optimize the energy efficiency of ship. This method will create a fundamental background in the field of improving energy efficiency of ships now a days.

\section{MATERIALS AND METHODS}

\section{Case study:}

M/V NSU JUSTICE 250,000 DWT: In Vietnam, the shipping transportation companies have a numerous

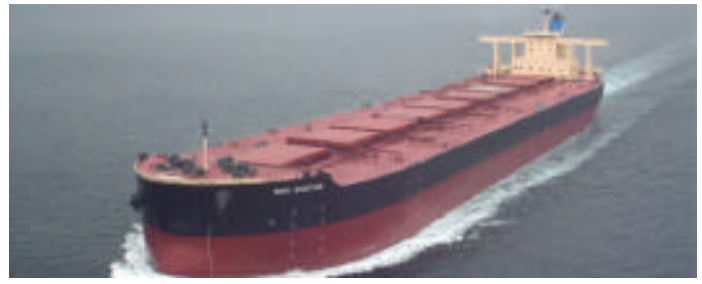

Fig. 4: M/V NSU JUSTICE 250,000 DWT

\begin{tabular}{lll}
\multicolumn{2}{l}{ Table 1: } \\
\hline Items & Categories & Parameters \\
\hline 1 & Vessel name & NSU JUSTICE \\
2 & IMO number & 9441922 \\
3 & MMSI & 373072000 \\
4 & Vessel type & Bulk carrier \\
5 & Gross tonnage & 132,868 \\
6 & Dead Weight Tonnage (DWT) & 250,000 \\
7 & Flag & Panama \\
8 & Draught & $18 \mathrm{~m}$ \\
9 & Speed Recorded (Max/Average) & $13.3 / 10.4 \mathrm{knots}$ \\
10 & Length $x$ Breadth $(\mathrm{L} \times \mathrm{B})$ & $329.95 \mathrm{~m} \times 57(\mathrm{~m})$ \\
11 & Year built & 2012 \\
\hline
\end{tabular}

number of ships with variety of sizes and types. There are a lot of shipping transportation companies where provide vessels and officers responding to develop the transportation business in domestic and international such as VINIC shipping transportation company associates with Vietnam Maritime University, Vietnam; VOSCO shipping transportation company, NISSHO shipping transportation company, etc. In this study, the target ship is used with a certain name M/V NSU JUSTICE 250,000 DWT of VINIC shipping transportation company. This is the biggest bulk carrier of company that operating on international routes. The experimental data has been collected from its operational activities. This vessel operates on the fixed routes between Japan-AustraliaBrazil. Table 1 presents these specification parameters of M/V NSU JUSTICE 250,000 DWT. In Figure 4 describes general of M/V NSU JUSTICE 250,000 DWT with design parameters show in Table 1.

$\mathrm{M} / \mathrm{V}$ NSU JUSTICE 250,000 DWT is powered by two-stroke main engine, single acting, crosshead, exhaust gas turbo-charged marine diesel engine with engine type of MAN B and W 7S80MC-C (Mark 7). Its Maximum Continuos Rating (MCR): $21,910 \mathrm{~kW}$ at the shaft rotational speed of $74.5 \mathrm{rpm}$. Furthermore, this vessel is powered by three main diesel generators with engine type of 4-stroke, single acting, turbo-charged diesel engine ( $₫ 21 \mathrm{AL}-\mathrm{SV}$ ). The Maximum Continuous Rating (MCR) is $880 \mathrm{~kW}$ at the respective shaft rotational speed of 900 rpm. On the other hand, this vessel is fitted the Fixed Pith Propeller (FPP) diameter $9.60 \mathrm{~m}$ with 4 blades. Especially, the vessel is equipped with a data acquisition system for 


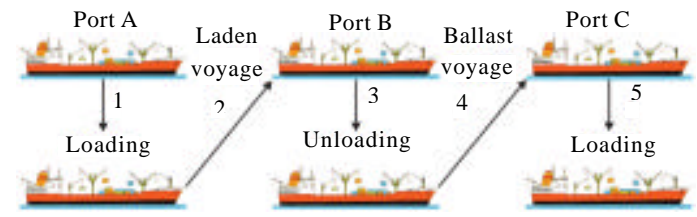

Fig. 5: The concept of ship voyage

\begin{tabular}{lc}
$\frac{\text { Table 2: EEOI value of M/V NSU JUSTICE } 250,000 \mathrm{DWT}}{2}$ & EEOI (Mass of CO per tonne.met) \\
\hline $\mathbf{I t e m s} /$ Voyage $\mathrm{N}^{\circ}$ & \\
$16 \mathrm{~A}$ & $4.1616 \mathrm{E}-04$ \\
$16 \mathrm{~B}$ & $5.6719 \mathrm{E}-04$ \\
$\mathbf{2}$ & \\
$17 \mathrm{~A}$ & $4.9504 \mathrm{E}-06$ \\
$17 \mathrm{~B}$ & $5.8613 \mathrm{E}-06$ \\
$\mathbf{3}$ & \\
$18 \mathrm{~A}$ & $5.0109 \mathrm{E}-06$ \\
$18 \mathrm{~B}$ & $6.2809 \mathrm{E}-06$ \\
$\mathbf{4}$ & \\
$19 \mathrm{~A}$ & $5.1751 \mathrm{E}-06$ \\
$19 \mathrm{~B}$ & $6.2269 \mathrm{E}-06$ \\
$\mathbf{5}$ & \\
$20 \mathrm{~A}$ & $5.0054 \mathrm{E}-06$ \\
$20 \mathrm{~B}$ & $5.509 \mathrm{E}-06$ \\
\hline
\end{tabular}

collecting the experimental data including the performance and navigation data. The performance and navigation data of this vessel with respect to the fuel consumption rates are considered in this study along with navigation conditions impact on ship.

Calculation of EEOI value for $\mathrm{M} / \mathrm{V}$ NSU JUSTICE 250,000 DWT: The EEOI calculation has an important position in enhancing the energy efficiency operation index of ships. In this case of study, the target ship is a bulk carrier with certain name M/V NSU JUSTICE 250,000 DWT. The researcher conducted to choose this type of ship because it is a popular ship that carries a numerous cargo in shipping transportation industry in the world and in particular, Vietnam. On the other hand, it has been chosen completely based on research situation and operational condition of shipping transportation companies in Vietnam.

To understand the difference between voyage 16A and $\mathrm{B}$ and similar for other voyage name. The concept of each voyage has been explained and described in Fig. 5 and Table 2 .

The mission of each voyage will carry out total five steps and showed in Fig. 5. Each step will represent a different operation condition. The loading and unloading cargo have been happening at cetain port (port A-C). Some related concepts have been defined as:

- A certain voyage includes having a cargo and no cargo $\left(m_{\text {cargo }}=0\right)$. The voyage name with $m_{\text {cargo }}=0$ has been assigned ballast voyage

- The time of voyage is the total of navigation time plus time when ship is at ports

- Each voyage will be defined by a time of period

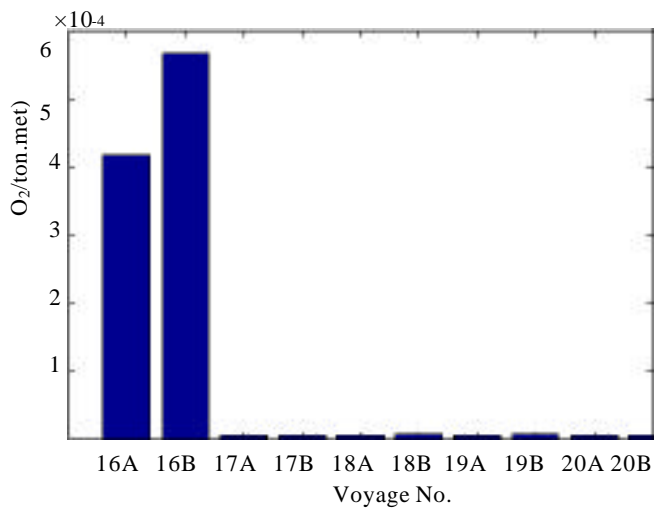

Fig. 6: EEOI values for M/V NSU ЛUSTICE 250,000 DWT

In this research, the voyage name $(16 \div 20)$ A will correspond to ballast voyage. The left voyages have a mass of fixed cargo. Since, the characteristic of each voyage is different between voyage having a cargo and no cargo, so, the EEOI of each voyage will have a certain value. The EEOI values of M/V NSU JUSTICE 250,000 DWT have been represented in Fig. 6.

Throughout Fig. 6, the Energy Efficiency Operational Indicator (EEOI) at each certain voyage is different. EEOI value for voyage No. 16 is the highest among other voyages. For other voyages their EEOI has small values. In this study, the recent voyages are used in calculation of EEOI index for M/V NSU JUSTICE 250,000 DWT that this vessel operating. These voyages almost carry bulk ore, so, there is nothing harmful good affects the Carbon dioxide $\left(\mathrm{CO}_{2}\right)$ emission to the environment. In addition it will not impact on the calculation of EEOI index following Eq. 1. So, the calculation results above of EEOI index for M/V NSU JUSTICE 250,000 DWT completely depend on the fuel consumption level of main engine.

\section{Optimization of experimental data for M/V NSU JUSTICE 250,000 DWT}

Taguchi method and Design of Experiment (DOE): Taguchi optimization method has been widely used in engineering analysis and it is a powerful method to optimize the energy efficiency of ships through experimental data. This method has been applied effectively in field of optimization. So, the researcher has used this method in aims with optimizing the experimental data of M/V NSU JUSTICE 250,000 DWT based on actual parameters collected at each voyage. The goals of this research would find out the optimal factors that decide to energy efficiency of ships based on the Energy Efficiency Operational Indicator (EEOI). The EEOI is an output 
Table 3: Selected input parameters and levels

\begin{tabular}{llllll}
\hline Controllable factors & Symbols & Units & Level 1 & Level 2 & Level 3 \\
\hline HFO fuel consumption & A & MT & 569.3 & 916.473 & 3027.57 \\
DO fuel consumption & B & MT & 2.9 & 10.4 & 21.9 \\
Cargo carried & C & MT & 123100 & 123438 & 123750 \\
Distance traveled & D & NM & 3456 & 4122 & 12286 \\
\hline
\end{tabular}

Table 4: Controllable factors with orthogonal array $\mathrm{L}_{9}$ of Taguchi method Controllable factors

\begin{tabular}{lllll} 
Experiment (No.) & A & B & C & D \\
\hline 1 & 1 & 1 & 1 & 1 \\
2 & 1 & 2 & 2 & 2 \\
3 & 1 & 3 & 3 & 3 \\
4 & 2 & 1 & 2 & 3 \\
5 & 2 & 2 & 3 & 1 \\
6 & 2 & 3 & 1 & 2 \\
7 & 3 & 1 & 3 & 2 \\
8 & 3 & 2 & 1 & 3 \\
9 & 3 & 3 & 2 & 1 \\
\hline
\end{tabular}

parameter in applying to the Taguchi method in this research. The number of controllable factors and levels, orthog onal array $\mathrm{L}_{9}$ is used in this research.

Furthermore, Taguchi optimization method uses a loss function to calculate the deviation between the experimental data and the desired value. The desired value of this research includes operation parameter of bulk carrier which ship operators desire. The mass of fuel oil consumption on ships is as smaller as better. This can be applied for both Heavy Fuel Oil (HFO) and Diesel fuel Oil (DO).

The reduction of energy consumption on ships will increase energy efficiency operational potential. This loss function is converted into a Signal-to-Noise $(\mathrm{S} / \mathrm{N})$ ratio. In addition, there are three types of quality characteristics in the analysis of the $\mathrm{S} / \mathrm{N}$ ratio: lower the better, higher the better and nominal the better. For each the controllable factors, the $\mathrm{S} / \mathrm{N}$ ratio will be calculated based on the $\mathrm{S} / \mathrm{N}$ ratio analysis. So, to increase the energy efficiency of ships then the EEOI values need to minimize. Therefore, the lower the better quality characteristic was used as shown in Eq. 2:

$$
\mathrm{S} / \mathrm{N}=-10 \log \left[\frac{1}{\mathrm{n}} \sum_{\mathrm{i}=1}^{\mathrm{n}} \mathrm{y}_{\mathrm{i}}^{2}\right]
$$

Where:

$\mathrm{y}_{\mathrm{i}}=$ The observed data at the ith experiment

$\mathrm{n}=$ The number of observations of the experiment

The controllable factors were used in Taguchi method including the Heavy Fuel Oil (HFO) consumption of engine (main diesel engine), Diesel Oil (DO) consumption, amount of cargo carried at each voyage and distance traveled along with their levels (Table 3).
Table 5: Analysis experimental data of M/V NSU JUSTICE 250,000 DWT Controllable factors

\begin{tabular}{|c|c|c|c|c|c|c|}
\hline \multirow{2}{*}{$\begin{array}{l}\text { Experiment } \\
\text { (No.) }\end{array}$} & & \multirow[b]{2}{*}{ EEOI } & \multirow[b]{2}{*}{$\mathrm{S} / \mathrm{N}$ ratio } \\
\hline & $\mathrm{A}$ & $\mathrm{B}$ & $\mathrm{C}$ & $\mathrm{D}$ & & \\
\hline 1 & 569.30 & 2.9 & 123100 & 3456 & 0.0004162 & 67.6150 \\
\hline 2 & 569.30 & 10.4 & 123438 & 4122 & 0.0005672 & 64.9250 \\
\hline 3 & 569.30 & 21.9 & 123750 & 12286 & 0.0000050 & 106.107 \\
\hline 4 & 916.47 & 2.9 & 123438 & 12286 & 0.0000059 & 104.640 \\
\hline 5 & 916.47 & 10.4 & 123750 & 3456 & 0.0000050 & 106.002 \\
\hline 6 & 916.47 & 21.9 & 123100 & 4122 & 0.0000063 & 104.040 \\
\hline 7 & 3027.57 & 2.9 & 123750 & 4122 & 0.0000052 & 105.722 \\
\hline 8 & 3027.57 & 10.4 & 123100 & 12286 & 0.0000062 & 104.115 \\
\hline$\underline{9}$ & 3027.57 & 21.9 & 123438 & 3456 & 0.0000055 & 105.179 \\
\hline
\end{tabular}

Furthermore, the orthogonal array $\mathrm{L}_{9}$ was selected to determine the optimal experimental data and to analyze the effects of these parameters. In Table 4, each controllable factor will be assigned its level through orthogonal array $\mathrm{L}_{9}$ of Taguchi optimization method.

Analysis of Signal to Noise (S/N) ratio of experimental data: The Energy Efficiency Operational Indicator (EEOI) was employed via. the experimental data design based on actual operational parameters on M/V NSU JUSTICE 250,000 DWT. The combination between EEOI and controllable factors (A-D) has been conducted by using Taguchi optimization method. The optimization of the measured control factors were provided by Signal-toNoise (S/N) ratios. The lowest values of EEOI is necessary to optimize energy efficiency of ships following MARPOL 73/78, Annex VI, Chapter IV. For this reason, the "lower the better" Eq. 2 was applied in this case to calculate the $\mathrm{S} / \mathrm{N}$ ratios. Table 5 shows the values of the $\mathrm{S} / \mathrm{N}$ ratios along with mean values corresponding to each experimental test when applying Taguchi orthogonal array $\mathrm{L}_{9}$ in this research.

In reality, the results of EEOI value has been decreased comparing with their initial values. It has proved that the energy efficiency of ship has been increased based on applying into Taguchi optimization method. The total mean value of energy efficiency operational indicator approaches 0.0001136 and total mean value of $\mathrm{S} / \mathrm{N}$ ratio is 96.483 . The application of Taguchi optimization method has contributed significantly in the field of improving energy efficiency of ships.

\section{RESULTS AND DISCUSSION}

Throughout the Taguchi optimization method, the optimal experimental data of M/V NSU JUSTICE 250,000 DWT has been determined for miniming the Energy Efficiency Operational Indicator (EEOI) in aims with optimizing energy efficiency of ships now a days. 


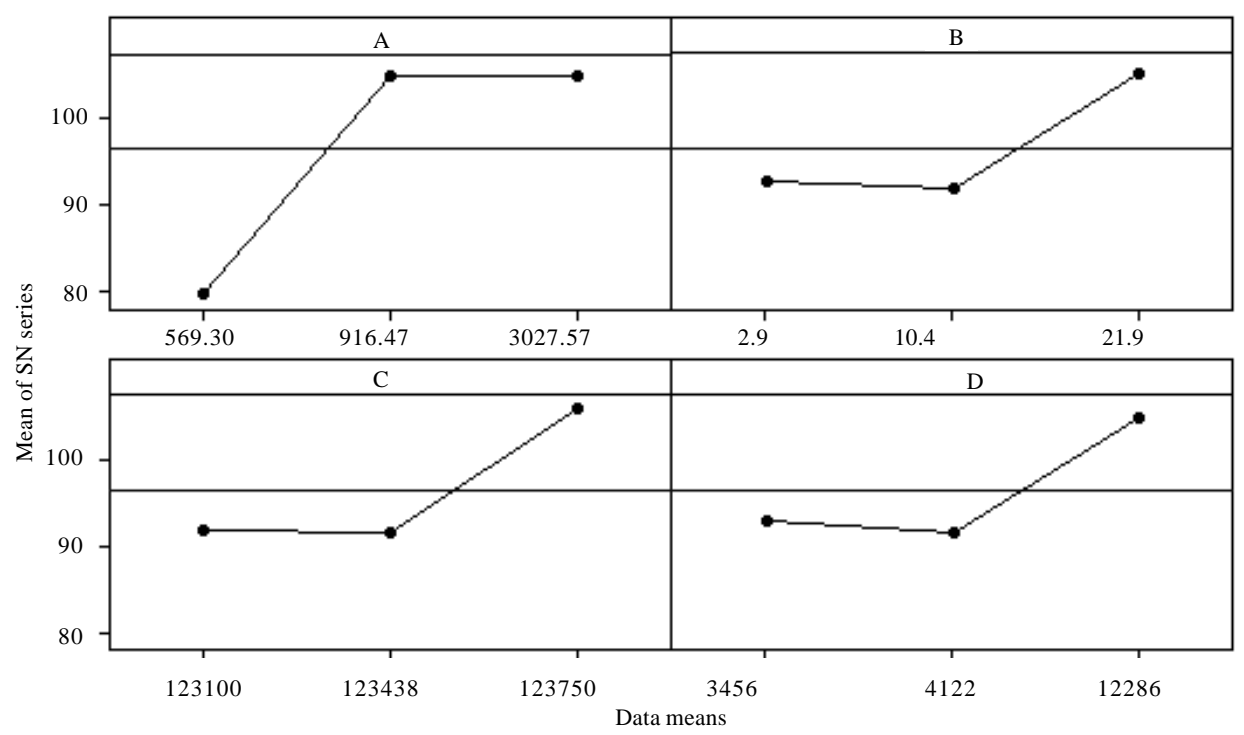

Fig. 7: Main effects plot for $\mathrm{S} / \mathrm{N}$ ratios (Signal-to-noise:smallar is better)

Table 6: Effect and ranking of mean for each controllable factors Controllable factors

\begin{tabular}{lllll} 
& & & & \\
Levels & A & B & C & D \\
\hline 1 & 0.000329 & 0.000142 & 0.000143 & 0.000142 \\
2 & 0.000006 & 0.000193 & 0.000193 & 0.000193 \\
3 & 0.000006 & 0.000006 & 0.000005 & 0.000006 \\
\hline
\end{tabular}

Delta: $0.000324,0.000187,0.000188,0.000187$; Ranking: 1.000000 , $3.000000,2.000000,4.000000$ and Optimum level: $1.000000,2.000000$, $2.000000,3.000000$

Table 7: Effect and ranking of $\mathrm{S} / \mathrm{N}$ ratios for each controllable factor Controllable factors

\begin{tabular}{lllll} 
Levels & $\mathrm{A}$ & $\mathrm{B}$ & $\mathrm{C}$ & $\mathrm{D}$ \\
\hline 1 & 79.55 & 92.66 & 91.92 & 92.93 \\
2 & $\mathbf{1 0 4 . 8 9}$ & 91.68 & 91.58 & 91.56 \\
3 & 105.00 & $\mathbf{1 0 5 . 1 1}$ & $\mathbf{1 0 5 . 9 4}$ & $\mathbf{1 0 4 . 9 5}$ \\
\hline
\end{tabular}

Delta: 25.460, 13.43, 14.36, 13.39; Ranking: $1.000 \quad 3.00, \quad 2.00, \quad 4.00$; Optimum level: $1.000,2.00,2.00,3.00$ : Bold values are significant values

The best level for each controllable factor has been found according to the highest Signal-to-Noise $\mathrm{S} / \mathrm{N}$ ratios in the levels of those controllable factors. In a result, the levels and $\mathrm{S} / \mathrm{N}$ ratios for factors giving the best Energy Efficiency Operational Indicator (EEOI) value have been specified as factor. A (Level 2, $\mathrm{S} / \mathrm{N}=104.89$ ), factor $\mathrm{B}$ (Level 3, S/N = 105.11), factor $\mathrm{C}($ Level 3, $\mathrm{S} / \mathrm{N}=105.94)$, and factor D (Level 3, S/N = 104.95) (Table 6 and 7).

The effect plots for $\mathrm{S} / \mathrm{N}$ ratios of each controllable factor have been described in Fig. 7 and compared with point of matching conditions, the optimum EEOI value will be achieved then the heavy fuel oil consumption rate of engine is in range of 916.47/3027.57 (MT-Metric Tonne) depends on different characteristics of each voyage, the diesel oil fuel consumption rate of engine is around 21.9 (MT), amount of cargo carried is about 123750 (Tons) and distance of each voyage is about 12286 (Knots).

In Table 6 and 7, the ranks of mean and $\mathrm{S} / \mathrm{N}$ ratios for controllable factors have been indicated in turn of from high to low. In particular, factor $D$ is the highest after that factor $\mathrm{B}, \mathrm{C}$ and $\mathrm{A}$ corresponding to all levels. From a result, Taguchi optimization method has been applied to indicate that optimization of experimental data for $\mathrm{M} / \mathrm{V}$ NSU JUSTICE 250,000 DWT needs to concentrate on optimizing the distance at each voyage. If this research happens then enhancement of energy efficiency of ships will gain the benefit. Moreover, the sea-going experience is very important in order to optimize the energy efficiency of ships. Due to, the role of ship's master plays a significant in aims with ensuring the ship just in time at destination ports but distance traveled is the shortest.

In reality, the comparison between proposed method and Grey Relational Analysis (GRA) method (Tran, 2017a, b) has been conducted in this research. In previous method, the results of ship energy efficiency optimization have only identified to give out the best optimal voyage among experimental data collected. Moreover, the determination of certain parameter needs to concentrate on ship operational process. The distance sailling parameter has been identified in the use of Grey Relational Analysis (GRA) method for saving the fuel oil consumption of vessel (Fig. 8).

In particular, the use of Taguchi optimization method has been represented effectively in the field of ships energy efficiency management. The proposed method has 


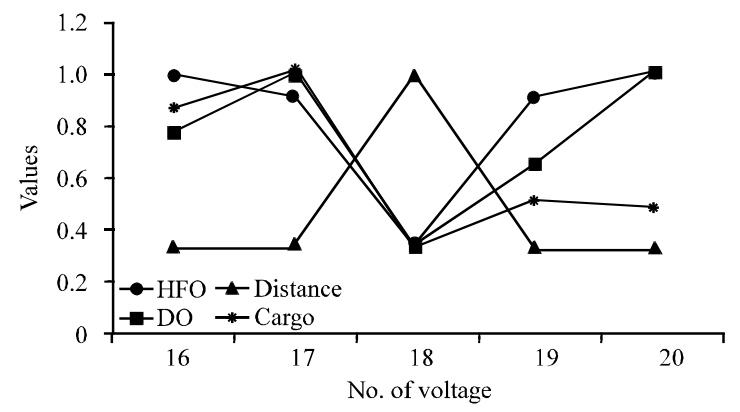

Fig. 8: The influence of operational parameters on ship energy efficiency management through GRA method (Tran, 2017a, b)

identified clearly the operational parameters which need to concern and pay attention in ships operational process.

\section{CONCLUSION}

The energy efficiency of ships plays an important role in creating "low carbon shipping" now a days. To conduct that in this study, Taguchi optimization method has been applied to determine optimal experiment data in the field of ship operation and management. From choosing a certain vessel with name $\mathrm{M} / \mathrm{V}$ NSU JUSTICE 250,000 DWT of VINIC shipping transportation company in Vietnam. This research can be carried out completely based on the operational experience of ship's master. Furthermore, the goal of this article is also indicated that application of Taguchi optimization method in shipping transportation is effective. It brings the benefit to ship's operator and manager in aims with ensuring safe operation, lowering the cost of fuel oil and protecting environment.

\section{ACKNOWLEDGEMENT}

The researcher wants to give a kindly thank to Key Laboratory of Marine Power Engineering and Technology (Ministry of Transportation), School of Energy and Power Engineering, Wuhan University of Technology, 1178 Heping Avenue, Wuhan 430063, China supports to complete this research.

\section{REFERENCES}

Altosole, M., M. Figari and M. Martelli, 2012. Time domain simulation for marine propulsion applications. Proceedings of the 44th Summer Conference on Computer Simulation Vol. 44, National Digital Science Library, Genoa, Italy, July 8, 2012, pp: 36-43.
Anonymous, 2014. Low Carbon shipping and air pollution control. International Maritime Organization (IMO), London, UK. http://www.imo. org/ en/MediaCentre/ HotTopics/GHG/Pages/default.aspx

Antony, J. and F.J. Antony, 2001. Teaching the Taguchi method to industrial engineers. Work Study, 50: 141-149.

Antony, J., 1998. Some key things industrial engineers should know about experimental design. Logistics Inf. Manage., 11: 386-392.

Athreya, S. and Y.D. Venkatesh, 2012. Application of Taguchi method for optimization of process parameters in improving the surface roughness of lathe facing operation. Intl. Refereed J. Eng. Sci., 1: 13-19.

Balaji, M., B.S.N. Murthy and N.M. Rao, 2016. Optimization of cutting parameters in drilling of AISI 304 stainless steel using Taguchi and ANOVA. Procedia Technol., 25: 1106-1113.

Banks, C., O. Turan, A. Incecik, G. Theotokatos and S. Izkan et al., 2013. Understanding ship operating profiles with an aim to improve energy efficient ship operations. Proceedings of the International Conference on Low Carbon Shipping, September 9-10, 2013, University of Strathclyde Faculty of Engineering, Glasgow, Scotland, pp: 1-18.

Buhaug, O., J.J. Corbett, O. Endresen, V. Eyring and J. Faber et al., 2009. Second IMO GHG study 2009. Master Thesis, International Maritime Organization (IMO), London, UK.

Chlela, F., A. Husaunndee, P. Riederer and C. Inard, 2007. A statistical method to improve the energy efficiency of an office building. Proc. Build. Simul., 1: 1756-1764.

Coraddu, A., M. Figari and S. Savio, 2014. Numerical investigation on ship energy efficiency by Monte Carlo simulation. Proc. Inst. Mech. Eng. Part M. J. Eng. Marit. Environ., 228: 220-234.

Ealey, L.A., 1994. Quality by Design Taguchi Methods and US Industry. 2nd Edn., Irwin Professional Publishing, Burr Ridge, Illinois,

Figari, M. and C.G. Soares, 2009. Fuel Consumption and Exhaust Emissions Reduction by Dynamic Propeller Pitch Control. In: Analysis and Design of Marine Structures, Soares, C.G. and ?P.K. Das (Eds.). CRC Press, Boca Raton, Florida, USA., ISBN:978-0-415-54934-9, pp: 567-574.

Johnson, H. and L. Styhre, 2015. Increased energy efficiency in short sea shipping through decreased time in port. Transp. Res. Part A. Policy Pract., 71: 167-178. 